УДК 811.124

\title{
ЛАТИНСКИЕ ЗООМОРФНЫЕ ТЕРМИНЫ В МЕДИЦИНСКОЙ ТЕРМИНОЛОГИИ
}

\author{
Скокова А.О., Олехнович О.Г. \\ Кафедра иностранных языков \\ Уральский государственный медииинский университет \\ Екатеринбург, Российская Федерация
}

\section{LATIN ZOOMORPHIC TERMS IN MEDICAL TERMINOLOGY}

\author{
Skokova A.O., Olekhnovich O.G. \\ Department of foreign languages \\ Ural state medical university \\ Yekaterinburg, Russian Federation
}

\begin{abstract}
Аннотация. Статья посвящена обзору и анализу зооморфных медицинских терминов на латинском языке, в основе которых лежат зоонимы - названия животных или их частей. Среди исследованных названий выделяются анатомические, клинические термины, фразеологизмы, простые и сложные термины и пр. Была произведена классификация терминов по морфологическим, синтаксическим, этимологическим и другим критериям.

Annotation. The article is devoted to the review and analysis of zoomorphic medical terms in the Latin language, which are based on zoononyms, the names of animals or their parts. Anatomical, clinical terms, phraseological units, simple and complex terms, etc. are distinguished among the studied names. The terms were classified according to morphological, syntactic, etymological and other criteria.
\end{abstract}

Ключевые слова: зооморфные термины, зоонимы, зооморфная метафора, словообразование.

Key words: zoomorphic terms, zoononyms, zoomorphic metaphor, word formation.

\section{Введение:}

Слово «зооморфный» греческого происхождения - оно состоит из двух греческих слов «zоo» 'животное’ и «morphe» 'форма', т. е. буквально означает 'имеющий отношение к форме животного'. В группу зооморфных медицинских терминов входят названия самого животного или его частей, которые имеют к ним какое-либо отношение.

Цель исследования - описать и проанализировать латинские зооморфизмы, используемые в медицинской терминологии.

Материалы и методы исследования: материалом для исследования послужили словари (Энциклопедический словарь медицинских терминов), а также статьи, из которых были выявлены названия анатомических, клинических, фармацевтических и других терминов, включающих в себя названия животных или их частей. Далее нами был проведен обзор и анализ названий. Были использованы семантический, сравнительный и статистический методы.

Результаты исследования и их обсуждение

Нами было отобрано более 100 зооморфных терминов разной структуры латинского и греческого происхождения (alopecia 'алопеция' < лат. alopex 'лисица' - выпадение волос; pterygium 'птеригий' < греч. pterygion 'крылышко'< уменьш. от греч. pteryx,-ygos 'крыло' - зарастание роговицы тканью конъюнктивы), среди которых мы рассматривали как отдельные термины, в которых используются зоонимы - названия животных и названий их частей, так и многословные термины, в основном фразеологизмы, в составе которых есть прилагательные, образованные от зоонимов (labium leporinum > 'заячья губа'; leporinus < лат. lepus,-oris n 'заяц'), Образы животных представлены в основном метафорическими терминами, которые формируются по разным признакам. Одни названия констатируют факт внешнего сходства с животными, их частями и особенностями их строения (ichthyosis 'ихтиоз' < греч. ichthys 'рыба' - ороговения кожи, напоминающие рыбью чешую). Другие отражают поведенческие особенности определённых животных (kynorexia 'кинорексия' < греч. kуn 'собака' и orexis 'желание есть'). Третьи непосредственно связаны с животными (ornithosis 'орнитоз' < ornis,-ithos 'птица' вирусное заболевание, передаваемое человеку птицами)

Что касается структуры зооморфных терминов, то среди них встречаются простые однословные термины латинского происхождения (lupus 'волчанка' < лат. lupus 'волк' - туберкулез кожи, при котором появляются язвы на лице; заболевание получило такое название, так как имеет разъедающий характер) и греческого происхождения (hippus 'гиппус' < греч. hippos 'лошадь' - приступообразное ритмическое сужение и расширение обоих зрачков длительностью в несколько секунд; термин назван по ассоциации со скачками лошади); сложные однословные (lagophthalmus 'лагофтальмус' (букв.) 'заячий глаз' < греч. lagos 'заяц' и ophthalmos 'глаз' - невозможность 
полностью закрыть глаз, по внешнему сходству с частью тела зайца); многословные термины (pectus gallinaceum 'куриная грудь' < лат. gallīna 'курица' - птичья грудь, суженная с обеих сторон грудная клетка с выпячивающейся вперед грудиной, основан на внешнем сходстве с частью тела курицы).

По способу словообразования выделяют термины, образовавшиеся при помощи суффикса (pediculōsis 'педикулез' < лат. pedicŭlus 'вошь' - заболевание кожи и волос, вызванное паразитами elephantiăsis,-is f 'элефантизм, слоновость, слоновая болезнь' < греч. elephas 'слон'- утолщение кожи и подкожной ткани; ichthyismus,-i m 'ихтиизм' < греч. ichthys 'рыба'- явления отравления рыбой; vaccīna,-аe $\mathrm{f}<$ лат. vacca 'корова' оспа на коровьем вымени; подобно натуральной оспе человека заболевание, но значительно более легкое). Более многочисленны термины, образовавшиеся приставочно-суффиксальным способом (derattisatio,-ōnis f 'дератизация’ < лат. rattus 'крыса’ - истребление грызунов, крыс, мышей; desinsectio ‘дезинсекция’ < лат. insectum 'насекомое' - уничтожение насекомых).

Отметим термины, образованные путём сложения (Hippocampus,-i m < греч. hippos 'конь' ‘гиппокамп' (рус. 'морской конек') - выпячивание в боковом желудочке мозга; aegrophonia,-ae f ‘эгофония’ < греч. aigos ‘коза' (рус. 'козий голос' «козье блеяние»).

В медицинской терминологии используются разные группы терминов: анатомические (сосhlea 'улитка' < греч. kochlos 'улитка' - передняя часть ушного лабиринта); клинические (elephantiăsis 'элефантизм' < греч. elephas 'слон' - «слоновая болезнь», увеличение размеров отдельных частей тела, сравнивается с размерами слона); фармацевтические (vaccīnum 'вакцина' < лат. vacca 'корова'); микробиологические (есhinococcus 'эхинококк' < греч. echinos 'еж’ - это ленточный глист, имеющий специальные крючья для прикрепления, напоминающие по форме иголки ежа); медицинской психологии (ріса 'пикацизм' < pica 'сорока' - извращенный аппетит, употребление в пищу несъедобных предметов; названо по ассоциации с аппетитом сороки).

С точки зрения морфологической классификации различаются: существительные (musculus 'мышца' < mus, muris m 'мышь' и уменьшит.-ласк. суффикса -cul-; antitrăgus,-i m 'противокозелок ушной раковины, лежащий против козелка' < греч. tragos 'козел’; Echinococcus, -i m 'эхинококк' (повод для этого названия дали хитиновые крючья сколекса, личиночная, пузырная стадия в различных органах промежуточного хозяина ленточного глиста Taenia < греч. echinos 'еж'); formicatio, ōnis $\mathrm{f}<$ лат. formǐca 'муравей'- чувство ползания мурашек, бегание мурашек, один из видов парестазии); прилагательные, образованные от названия животных, которые входят в состав многословных терминов (anserīnus,-a,-um 'относящийся к гусю или напоминающий гуся'< лат. anser,- eris m ‘гусь' - cutis anserina ‘гусиная кожа' пиломоторная реакция кожи под влиянием холода, cтраха; leporīnus,-a,-um 'относящийся к зайцу или напоминающий зайца' < лат. lepus,-oris n 'заяц' -labium leporium 'заячья губа').

\section{Выводы:}

1. Нами был произведен обзор и анализ медицинских терминов, в основе которых используются зооморфизмы.

2. Нами была произведена классификация терминов по морфологическим, лексическим синтаксическим, этимологическим и другим критериям.

\section{Список литературы}

1. Архипова И.С., Дрикер М.Б., Олехнович О.Г., Ольшванг О.Ю., Тихомирова А.B. TERMINOLOGIA MEDICA LATINA. Латинская медицинская терминология. Учебное пособие по латинскому языку для студентов лечебных факультетов медицинских вузов. Екатеринбург: УГМУ, 2019. - 223 с.

2. Лаптева Е.А. Образ животного в медицинских терминах на латинском, русском, английском, немецком языках. [Электронный ресурс] // Гуманитарные исследования. - $2016 . \quad$ - №2. URL: https://cyberleninka.ru/article/n/obraz-zhivotnogo-v-meditsinskih-terminah-na-latinskom-russkom-angliyskomnemetskom-yazykah/viewer (дата обращения: 24.01.2020)

3. Марудова A.C. К вопросу о содержании термина «зооним». [Электронный pecypc] URL: http://elib.bsu.by/bitstream/123456789/148159/1/\%D0\%9C\%D0\%B0\%D1\%80\%D1\%83\%D0\%B4\%D0\%BE\%D0\%B2 $\%$ D0\%B0\%20\%D0\%90.\%D0\%A1.\%20\%D0\%9A\%20\%D0\%92\%D0\%9E\%D0\%9F\%D0\%A0\%D0\%9E\%D0\%A1\%D0 $\% \mathrm{~A} 3 \% 20 \% \mathrm{D} 0 \% 9 \mathrm{E} \% 20 \% \mathrm{D} 0 \% \mathrm{~A} 1 \% \mathrm{D} 0 \% 9 \mathrm{E} \% \mathrm{D} 0 \% 94 \% \mathrm{D} 0 \% 95 \% \mathrm{D} 0 \% \mathrm{~A} 0 \% \mathrm{D} 0 \% 96 \% \mathrm{D} 0 \% 90 \% \mathrm{D} 0 \% 9 \mathrm{D} \% \mathrm{D} 0 \% 98 \% \mathrm{D} 0 \%$ 98\%20\%D0\%A2\%D0\%95\%D0\%A0\%D0\%9C\%D0\%98\%D0\%9D\%D0\%90\%20\%C2\%AB\%D0\%97\%D0\%9E\%D0\%9 E\%D0\%9D\%D0\%98\%D0\%9C\%C2\%BB.pdf (дата обращения: 27.02.2020)

4. Рябова А.М., Козлова Е.А. Зоонимы в медицинской терминологии. [Электронный ресурс] // Журнал Гродненского государственного медицинского университета. - $2012 . \quad$ - №3. URL: https://cyberleninka.ru/article/n/zoonimy-v-meditsinskoy-terminologii/viewer (дата обращения: 24.01.2020)

5. Энциклопедический словарь медицинских терминов: В 3-х томах. Около 60000 терминов / гл. ред. Б. В. Петровский. - М.: Советская энциклопедия, 1984. - 512 с. 